\title{
A Study on the Deng's Cultural Identity of Ethnic Group in NyingChi of Tibet
}

\author{
Hui LUO ${ }^{1, a,{ }^{*}}$ and Qiu-lian JIN²,b \\ ${ }^{1,2}$ School of Journalism and Communication, Xiamen University, Fujian, P.R.China \\ aluohui824@foxmail.com, b1139613764@qq.com,
}

Keywords: Deng, Ethnic Group, Cultural Identity, Cross-cultural Communication.

\begin{abstract}
China is a multi-ethnic country with cultural diversity. In addition to the 56 identified ethnic groups, there is a special ethnic group called the Deng which have not been identified as an official ethnic group until now. Some of them have lived in Nyingchi located in the southeastern part of Tibet. In the 1950s, the Deng and the local Tibetan were liberated and lived in the socialist society from the primitive society, which led to the evolution of civilization and the improvement of living standards. Nowadays, except for the problem of identity traceability, the Deng are also facing the problem of ethnic group's cultural identity and inheritance. Based on the Deng who have already received higher education with the ages between 16 and 60 years old as the research objects, this paper analyzes the current situation and attitudes of cultural identity of ethnic group of the Deng through questionnaires and in-depth interviews and then provides some thoughts on the ways that refer to both promoting cross-cultural communication and protecting the cultural diversity.
\end{abstract}

\section{Introduction}

China is a multi-ethnic country. Since the founding of the People's Republic of China, the government has started to carry out the work of ethnic groups' identification in order to establish an open ethnic environment with ethnic characteristics and implement the policy of ethnic equality. By 1987, 55 ethnic minorities have been identified officially. Besides, there are still some unidentified ethnic groups. Becauce there are not historical records and sufficient data as powerful evidences to identify them. So some ethnic problems have been left till now. Among them, the Deng is one of the unidentified ethnic minorities.

The ethnic groups of the Deng are distributed in the border area between China and India. The Deng of China mainly live in Zayü County of NyingChi City in Tibet Autonomous Region. The total number of them is about 2000. [1] In the 1950s, the Deng and the local Tibetan were liberated by People's Liberation Army of China. They helped the Deng to move out from deep mountains and teached them the plant techniques with the land reclamation. Then the Deng formed the new settlements in the foot of the mountain eventually. Before this, the Deng had lived a primitive life in slash-and-burn cultivation without much contact with the outside world. Because there were not written records about them in detail, the history of the Deng could be remembered only in form of word of mouth which could trace back to the Deng's history about three hundred years ago. However, word of mouth led to blind spots directly in the Deng's historical records because of a large number of missing information. So the traceability was hindered and the identity of the Deng's ethnic group could not be confirmed historically. 
Except the problem of identity traceability, the Deng have faced the problem of ethnic group's cultural identity and inheritance at present. Since the liberation of Tibet, all kinds of bad habits were abolished. And the living standards were also improved significantly by changing the mode of production. At the same time, more and more people of the Deng were educated. Now there are primary school students, junior high school students, high school students as well as college students and undergraduate students in the ethnic group of the Deng. [2] On the one hand, these changes promote the better integration of them into modern civilization society. On the other hand, it also brings some challenges to the cultural identity and cultural inheritance of their own ethnic group. Based on the Deng that have received higher education with the ages between 16 and 60 years old as the research objects, this paper analyzes the current situation and attitudes of ethnic group of the Deng through questionnaires and in-depth interviews and then provides some thoughts on the ways that refer to both promoting cross-cultural communication and protecting the cultural diversity.

\section{The Current Situation of the Deng's Cultural Identity of Ethnic Group}

The two concepts of "ethnic group" and "nation" came from the western academic terms. Max Weber saw ethnic groups broadly as "human groups that entertain a subjective belief in their common descent - because of similarities of physical type or of customs or both, or because of memories of migration - in such a way that this belief is important for the continuation of the nonkinship communal relationships". [3] The concept of nation emerged after nation-stated appeared. Benedict Anderson, an American scholar, said that the modern concept of nation appeared when the identity of people in nation state countries changed from subject to citizenship in the 17th century. Therefore, the concept of nation was always considered to be with identity of nation state. [4]

In the context of China, there are different meaning between the concept of ethnic group and the concept of nation. The concept of ethnic group is applied to the cultural meaning of nation and the concept of nation is applied to the political meaning of ethnic group. [5] So the concept of ethnic group emphasizes the cultural aspects of the community and the concept of nation stressed the political aspects of the community. [6] Ethnic identity are always based on cultural identity that reflect in a series of cultural elements. For one thing, the basic elements of identity include the common historical memories in the ethnic group. For another, the general elements of identity mainly containing the language, religion, geography, customs and other aspects. [7] Combined with the basic elements of identity and the general elements of identity together, this paper investigates and analyzes the current situation of the Deng's cultural identity of ethnic group in NyingChi from the following three aspects.

\section{The Material Dimension of Costume Culture}

The Deng live in the southeast of Tibet and India at the junction. To some extent, their ethnic costumes are influenced by the India costumes. The costumes of the Deng are mainly made by linen-based fabrics and dyed with barks in red and black. A survey found that almost everyone of the Deng had their own ethnic costumes. But now, ethnic costumes are rarely put on. Only the older women in the group still have a habit of wearing traditional costumes. The others, especially the youngers, almost wear modern dresses in daily life. 
Through interviews, we found the following situations. Those who had engaged in the work would dress in ethnic costumes in order to show their identity when attending large meetings or events. Students would put on ethnic costumes while taking participate in campus activities associated with ethnic minorities. Some families would wear ethnic costumes and then take pictures for important memory. All in all, although the Deng always wear modern dresses now, the most of them will put on ethnic costumes on important occasions to show their cultural identity of ethnic group.

The replacement of traditional costumes is a problem that every ethnic minority need to faces. There are two reasons for the replacement of traditional costumes of the Deng. Firstly, Deng people usually choose to put on more simple and convenient clothes in order to adapt to the development of the times. Secondly, there is inheritance crisis of the technology that is how to make the traditional costumes. The older generation of weavers are getting older. The tedious work of manufacture of ethnic costumes cannot attract the interest and attention of the youngers. Although the traditional costumes are inevitable to be replaced by modern dresses, the Deng's attitudes towards the ethnic costumes are positive. They try to demonstrate the unique material culture of costumes on every possible occasion.

\section{The Behavioral Dimension of Language Culture}

The language of the Deng belongs to the Tibeto-Burman languages. The Deng have their own language without words. The narrative history have been communicated from generation to generation mainly by word-of mouth. The language of the Deng are divided into two different types according to the two clan classification, respectively Digaro-Mishmi and Miju-Mishmi.Although the Digaro-Mishmi as a common language are usually used both in the two clans, Miju-Mishmi are used a lot in its own clan.

According to the analysis of the interviews, it is found that the Deng with different ages were quite different in the aspects of learning and using of the ethnic language. The Deng over the age of 30 not only could use the language of Digaro-Mishmi as common language expertly, but also could understand the language of Miju-Mishmi and use the basic language of Miju-Mishmi to a certain extent. On the contrary, those younger than 30 could only use the language of Digaro-Mishmi expertly. Only a few of them younger than 30 could understand the simple vocabulary of Miju-Mishmi. With the emergence of intermarriage between the Deng and the other ethnic groups, some of them could not understand both two types of ethnic language of the Deng completely.

With the gradual weakening of the use of ethnic language, the name of the Deng became in the form of Chinesization gradually. Before the 1980s, the Deng usually used the surname of their clan in the documents and interviews. Now the surname of their clan are rarely used in the name. The surname of their clan are mentioned between each other only in the internal communication. Further study on the name of the Deng found different situations as follows. The name of the Deng over the age of 45 were generally transliterated. The name of the Deng between the ages of 30-45 began to use Chinese name directly. And more and more Chinese characters were used in the name of the Deng under the age of 30. Besides, a few of Tibetan name were used in the next generation after the intermarriage between the Deng and Tibetan.

There are many reasons for the weakening usage of ethnic language of the Deng. Firstly, it is due to the changes of language environment. In the primitive society before, the Deng did not communicated with other ethnic groups. But now when they begin to communicate with other ethnic groups, they will use other common languages in order to be understood by others easily. Especially for those who study and work far away 
from their own ethnic districts, they seldom use the ethnic language of the Deng. Secondly, the family does not pay enough attention to the use of language and teach their children to use the ethnic language expertly. At the same time, there are not official institutions or schools that teach people how to use the ethnic language. Finally, the ethnic language are only used and disseminated in their own ethnic group, which make others are difficult to know the exist and the meaning of the Deng's language.

\section{The Spiritual Dimension of Belief Culture}

The Deng had been living in the primitive society for a long time before. They did not understand the natural growth and the phenomena of illness and death. Due to being awe of nature, they took all the phenomena they didn't understand as the natural myths. What's more, they advocated that everything had soul with the fear of the ghosts, which were demonstrated as all kinds of taboos in daily life. Taking the taboo of the funeral as example, they thought that everyone would become a ghost after death. So they could not mention the names of the person who had died because of the fear of the ghosts. Moreover, the members who were not belong to the same clan were forbidden to participate in the funeral. Besides, there were other taboos in catering culture. For example, if they ate in the forest or valley, the foods were needed to be dedicated to the local ghost to eat first. The fear of ghosts was also reflected in the ceremony of ghost delivery that were hosted usually by psychic person or wizard. When the members of family were sick or died or moved into new house, the wizard would be invited to hold the ceremony of ghost delivery. Although some taboos of words and deeds mentioned above have existed in a way till now, spiritual faith have begun to blur.

The ambiguity of spiritual belief is affected by many factors. Firstly, with the development of modern society, the Deng have a new understanding of the science. When they get sick, they will consider the scientific methods after the traditional ceremony of ghost delivery hosted by the wizard. Secondly, there are less successors of the profession of the wizard. Because of the high social status in the ethnic group of the Deng, the selection processes of the wizard are relatively rigorous in many aspects. And now the younger generation of the Deng are not interested in the career of the wizard. If this profession cannot be inherited, then communicator of spiritual beliefs will disappear in the future. Thirdly, the Deng in China mainly live in the Tibetan Autonomous Region. With the close contact with Tibetan, words and deeds of the Deng have been affected by Tibetan compatriots and Tibetan Buddhism in the long run.

\section{Some Thoughts on Maintaining the Ethnic Culture of the Deng}

\section{Protecting the Excellent Culture Elements of the Deng's Ethnic Group}

General speaking, ethnic identity are usually manifested in two aspects. In the aspect of attitude, the members of ethnic groups have cognitive and emotional attachment to their ethnic affiliation. [8] In the aspect of practice, the members of ethnic groups make practical actions for the inheritance of ethnic culture. According to the results of 62 questionnaires and 12 interview reports, it is found that the extent of the Deng's cultural identity of ethnic group was not very high. In the aspect of understanding of the history and custom of their own ethnic group, 59\% of the Deng thought that they knew a little about them. While only $25 \%$ of the Deng thought that they knew them very well. Besides, $86 \%$ of the Deng thought that the traditional culture were not maintained and inherited very well. Actually, there are many reasons that the Deng do not know enough 
about their ethnic history and culture. For one thing, there is no written records left untill now, which lead to the difficulty of historical traceability. For another, the members of ethnic group don't pay enough attention to keep the history and inherit the culture from one generation to another.

In fact, the disappearance of part of the cultural customs of the Deng are the results of the civilization progress, such as the abolition of the mercenary marriage and polygamy phenomenon. However, while introducing the scientific concepts and the modern ways of life into the ethnic group of the Deng, it is very important to preserve and inherit the unique essence of the Deng's culture to maintain the cultural diversity of the ethnic groups. In view of cultural aspects that mentioned above, we can try to make efforts from the following aspects.

First of all, in terms of ethnic costumes, the traditional technology of costume textile need to be protected and inherited. And it is necessary to encourage the younger generation to use new media and other mass media channels to disseminate the various material culture of the Deng. Secondly, in terms of language usage, local government can do more jobs of language collection and strengthen the protection of the ethnic language. And families should pay attention to the use of their own language. They can make some rules that all members of the family need to speak the ethnic language at home. Moreover, if some of them get marriage with others who are not belong to their ethnic group, it is better to learn both of the two ethnic languages at the same time. Thirdly, in terms of religious belief, the popularization of the science concepts has led to the decrease in religious taboos. Although the Deng do not have their own written words until now, they can record the origin and the change of the religious belief in detail in Chinese. Then it is more convenient for the younger generation to know and research the religious history and culture through written records in the future.

\section{Promoting Cultural Integration in Communication with Other Ethnic Groups}

The protection of the Deng's ethnic culture does not mean that the Deng do not need to communicate with other people from different cultural backgrounds. In the contrast, the mobility of society promotes cross-cultural communication among different ethnic groups, in which people in different cultural backgrounds will be affected with each other. So it is more worthy to think about the ways to coordinate the relationship between the ethnic culture of the Deng and the mainstream culture in the course of the cross-cultural communication.

John W. Berry's theory in acculturation consists of two related components. One is the attitudes that an individual's preference about maintaining the traditional culture and identity. The other is the behaviors that a person's actual activities that are exhibited in day-to-day intercultural communication. Combined with the interaction between non-dominant culture and dominant culture, there are four acculturation strategies. When the dominant peoples adopt the strategy of melting pot, segregation, exclusion and multiculturalism respectively towards the non-dominant peoples, the non-dominant peoples respond with the strategy of assimilation, separation, marginalization and integration respectively. [9] According to John W. Berry's theory above, the best strategy for the protection of the Deng's ethnic culture is integration that requires two components. For one thing, multiculturalism strategy need to be implemented by the dominant acculturating groups to maintain the diversity between different cultures. For another, there should be an interest in both maintaining the Deng's heritage culture in daily interactions with other ethnic groups and seeking to participate as an integral part of the larger social network through integration as a member of an ethnocultural group. 
Combined with the two components above, integration can promote the emergence of the new culture that belongs to different ethnic groups in the course of the interaction and cross-cutural commnication.

In October 2005, the General Conference of the United Nations Educational, Scientific and Cultural Organization adopted the convention on the Protection and Promotion of the Diversity of Cultural Expressions. The conference affirms that cultural diversity is a defining characteristic of humanity. Being aware that cultural diversity creates a rich and varied world, which increases the range of choices and nurtures human capacities and values, and therefore is a mainspring for sustainable development for communities, peoples and nations. [10] Since the cultural diversity forms a common heritage of humanity and should be cherished and preserved for the benefit of all, it is important to choose the best cultural heritage and protect them in a way. It is a long-term work to maintain the cultural diversity of the ethnic groups and promote the cross-cultural communication between different ethnic groups to integrate and form new culture.

\section{Acknowledgement}

The paper is supported both by the Project of National Social Science Foundation (project number: 16CXW002) and by the Fundamental Research Funds for the Central Universities (project number: 20720151160).

\section{References}

[1] Wang Jian, Ding Wu-jun, Report on the Living State of Dengren in Cayu, Journal of Jiangxi Science \& Technology Teachers' College. 4 (2002), 11-15.

[2] GeSang Gong-bu, Deng: Coming from the Mountains, China's Tibet (Chinese Version). 1 (2008) 16-23.

[3] Marx Weber, the Ethnic Group, in: Talcott Parsons etal (Eds.), Theories of Society: Foundations of Modern Sociological Theory (Vol.1), Free Press of Glencoe, New York, 1961, p306.

[4] Liu Hai-tao, On the Construction of Ethnic Group and the Identity of Nation State, Guizhou Ethnic Studies. 4 (2006) 11-15.

[5] Guo Zhi-qian, Huang Shu-ping, Cultivation of Ethnie Identity — a Preliminary Study on Protecting Minority Culture, Social Sciences Journal of Universities in Shanxi. 6 (2012)73-76.

[6] Qin Nai-chang, From Ethnic Identity toward National Identity: Third Research on Guangxi's National Recognition in Mid-and Late 20th Century, Study of Ethnics in Guangxi. 3 (2009) 22-31.

[7] Zhou Da-ming, Some Problems Concerning Ethinic Groups Studies in China, Journal of Guangxi University for Nationalities Journal of Guangxi University for Nationalities. 2 (2009) 2-10.

[8] Wang Xi-en, Ethnic Identity and Ethnic Consciousness, Ethno-National Studies, 6 (1995)17-21.

[9] John W.Berry, Acculturation: Living Successfully in Two Cultures, International Journal of Intercultural Relations, 29 (2005) 697-712. 
[10] UNESCO: http://unesdoc.unesco.org/images/0014/001429/142919e.pdf. 